9 Brady J. The association between alcohol misuse and suicidal behaviour. Alcohol Alcohol 2006; 41: 473-8.

10 Wilkinson S, Taylor G, Templeton L, Mistral W, Salter E, Bennett P. Admission to hospital for deliberate self-harm in England 1995-2000: an analysis of Hospital Episodes Statistics. J Public Health Med 2002; 24 $179-83$

11 Haw C, Hawton K, Casey D, Bale E, Shepherd A. Alcohol dependence, excessive drinking and deliberate self-harm: trends and patterns in Oxford, 1989-2002. Soc Psychiatry Psychiatr Epidemiol 2005; 40: 964-71.

12 Babor TF, Higgins-Biddle JC, Saunders JB, Monteiro MG. AUDIT: The Alcohol Use Disorders Identification Test - Guidelines for Use in Primary Care. World Health Organization, 2001

13 Association of Public Health Observatories. Health Profile 2007: Northumberland. APHO, 2007.

14 Saunders JB, Aasland OG, Babor TF, De La Fuente JR, Grant M Development of the Alcohol Use Disorders Identification Test (AUDIT): WHO Collaborative Project on Early Detection of Persons with Harmful Alcohol Consumption II. Addiction 2002; 88: 791-804.

15 Maisto SA, Carey MP, Carey KB, Gordon CM, Gleason JR. Use of the AUDIT and the DAST-10 to identify alcohol and drug use disorders among adults with a severe and persistent mental illness. Psychol Assessment 2002; 12: 186-92.
16 Allen JP, Litten RZ, Fertig JB, Babor T. A review of research on the Alcohol Use Disorders Identification Test (AUDIT). Alcohol Clin Exp Res 1997: 21: 613-9.

17 Hawton K, Fagg J, McKewon S. Alcoholism, alcohol and attempted suicide. Alcohol Alcohol 1989; 24: 3-9.

18 British Medical Association, Royal Pharmaceutical Society of Great Britain. British National Formulary 56. RPS Publishing, 2008.

19 Association of Public Health Observatories. Health Profile 2007: Oxfordshire. APHO, 2007.

20 Association of Public Health Observatories. Health Profile 2007: Oxford. APHO, 2007.

21 Association of Public Health Observatories. Health Profile 2007: Blyth APHO, 2007.

22 Association of Public Health Observatories. Health Profile 2007: Wansbeck. APHO, 2007

23 Craig R, Mindell J. Health Survey for England 2006 Latest Trends. The Information Centre, 2008 (http://www.ic.nhs.uk/webfiles/publications/ HSE06/Health\%20Survey\%20for\%20England\%202006\%20Latest \%20Trends.pdf)

24 NHS Quality Improvement Scotland. Harmful Drinking Three: Alcohol And Self-Harm. Scottish Emergency Department Alcohol Audit. NHS Quality Improvement Scotland, 2007.

\title{
Effectiveness and confusion of the Time to Change anti-stigma campaign
}

\author{
Abu Abraham, ${ }^{1}$ Joby M. Easow, ${ }^{2}$ Palanisamy Ravichandren, ${ }^{3}$ Salman Mushtaq, ${ }^{4}$ \\ Linda Butterworth, ${ }^{4}$ Jason Luty ${ }^{4}$
}

The Psychiatrist (2010), 34, 230-233, doi: 10.1192/pb.bp.109.027052

${ }^{1}$ Basildon Hospital; ${ }^{2}$ Community Drug and Alcohol Service, Pitsea, Basildon ${ }^{3}$ Runwell Hospital, Wickford; ${ }^{4}$ Taylor Centre, Southend-on-Sea, UK

Correspondence to Jason Luty (sl006h3607@blueyonder.co.uk)
Aims and method Several national anti-stigma campaigns have been devised in the UK, including the current Time to Change campaign in England. Our aim was to assess whether the campaign promotional materials were likely to have any effect on public attitudes towards mental illness. Postcards, leaflets and bookmarks promoting the campaign were posted to 250 participants recruited from a representative panel of members of the public. Two weeks later a questionnaire was sent to assess the impact the campaign materials had.

Results The response rate was $78 \%$. Only $23 \%$ of participants recognised the Time to Change logo after 2 weeks and only $20 \%$ correctly reported that one in four people were affected by mental health problems when presented with five alternative responses. Almost as many participants thought the campaign was promoting a British political party rather than discrimination against mental illness.

Clinical implications A single exposure to Time to Change campaign materials is unlikely to be effective. The title of the campaign is likely to be confused with political campaigning in Britain.

Declaration of interest None.
Stigma is a social construction that devalues people because of a distinguishing characteristic or mark. ${ }^{1}$ The World Health Organization and the World Psychiatric Association recognise that the stigma attached to mental disorders is strongly associated with suffering, disability and poverty. ${ }^{2}$ Stigma is also a major barrier to seeking treatment. ${ }^{3}$ Many studies show that negative attitudes towards the mentally ill are widespread, while the media 
generally depict mentally ill people as violent, erratic and dangerous. 4,5

Providing factual information in brief fact sheets ${ }^{6-8}$ or through extensive interventions such as educational courses is reported to reduce stigma. ${ }^{9-11}$ These methods have been the basis of several anti-stigma campaigns. For example, the Royal College of Psychiatrists' Changing Minds campaign aimed to promote positive images of mental illness, challenge misrepresentations and discrimination, and educate the public to the real nature and treatability of mental disorder. ${ }^{5}$ This campaign contributed towards Action on Mental Health: A Guide to Promoting Social Inclusion, a document of 12 fact sheets on reducing the stigma of mental illness, with practical advice to health agencies, employers and stakeholders. ${ }^{12}$ More recently, national anti-stigma campaigns have been launched in Scotland (www.seeme scotland.org.uk) and England (www.time-to-change.org.uk). Unfortunately, there have been reports that national antistigma campaigns are not particularly effective. ${ }^{13-15}$ These reports discuss the disappointing results from the English Defeat Depression and Changing Minds campaigns and the (Scottish) See Me campaign.

We wanted to assess whether promotional materials from the Time to Change campaign (postcards, leaflets and bookmarks) were likely to have any effect on public attitudes towards mental illness.

\section{Method}

\section{Participants}

We identified a panel of 250 participants from the UK general population recruited using direct mail-shots and adverts in local newspapers as described in a previous study. ${ }^{16}$

\section{Procedure}

Each participant was posted a Time to Change postcard, leaflet and bookmark, where it was clearly stated that mental health problems affect ' 1 in 4 people'. Two weeks later a questionnaire was posted out (see online supplement to this article). The attitude of participants towards mental illness was tested using the 5-item Attitude to Mental Illness Questionnaire (AMIQ), with a vignette describing a man with depression and an episode of self-harm. The questionnaire also enquired about participants' gender, age, ethnicity and employment status, recognition of the Time to Change logo, awareness of the ' 1 in 4 ' slogan and the purpose of the Time to Change campaign.

\section{Instruments}

The 5-item AMIQ is a brief self-completion questionnaire. ${ }^{16,17}$ Respondents read a short vignette describing an imaginary patient and answered five questions relating to it (online supplement). The questions were scored on a 5-point Likert scale (maximum +2, minimum-2), with blank questions, 'neutral' and 'don't know' scoring zero. The total score for the vignette ranged between -10 and +10 . The AMIQ has been shown to have good psychometric properties in a sample of over 800 members of the UK general public (one component accounted for $80.2 \%$ of the variance; test-retest reliability was $P=0.702$; alternate testreliability $v$. Corrigan's attribution questionnaire was 0.704 (Spearman's Rho); Cronbach's $\alpha=0.93$ ). ${ }^{16}$

\section{Results}

Completed questionnaires were received from 196 individuals (response rate 78\%); 32\% were male; mean age was 50 years $($ s.e. $=1.1)$; $56 \%$ were in paid employment; $92 \%$ described themselves as White British; $41 \%$ endorsed the item 'Do you know anyone personally who has a serious mental illness (like schizophrenia) or someone who has been in a mental hospital?'

The mean score was +1.92 (s.e. $=0.29$; s.d. $=2.91$ ) for the 5-point AMIQ stigma scale. We compared this with a score from the AMIQ validation 3 years earlier on 1098 members of the UK general public: + 2.35 $($ s.e. $=0.10){ }^{16}$ There was no statistically significant difference in scores (Mann-Whitney $U$-test two-sided $P=0.0367$; power $($ for $5 \%$ significance $)=55 \%$ ).

\section{Campaign recognition}

The campaign logo was recognised by $23 \%$ of participants. However, only $17 \%$ stated that they had ever heard of the Time to Change campaign. Only $20 \%$ correctly reported that one in four people were affected by mental health problems when presented with five alternative responses (33\% chose one in three; $14 \%$ one in five; $12 \%$ one in six; and $34 \%$ did not know). When asked 'What issue or organisation does the Time to Change campaign promote?' and presented with six alternatives, $24 \%$ correctly identified 'discrimination against mental illness'. However, 57\% endorsed 'Don't know/None of the above,' and 20\% endorsed 'The Liberal Party'.

\section{Familiarity with mental illness}

Overall, 82 (42\%) participants had contact with a mentally ill person. Still, familiarity with mental illness had no significant effect on the AMIQ stigma scores or familiarity with the campaign. The 45 participants who recognised the campaign logo had a significantly increased chance of correctly identifying the objective of the campaign (Yatescorrected $\chi^{2}=6.95 ; P=0.0084 ; \mathrm{OR}=2.74(95 \%$ CI 1.34-5.6)), but they had a reduced chance of identifying the ' 1 in 4 ' catchphrase (Yates-corrected $\chi^{2}=0.02 ; P=0.8983 ; \mathrm{OR}=0.88$ (95\% CI 0.4-1.93)).

\section{Discussion}

A single exposure to three forms of promotional materials from the Time to Change anti-stigma campaign (postcards, leaflets and bookmarks) had little discernable effect on public attitudes towards mental illness. There was no significant change on scores of the AMIQ when performed in respect to a fictitious man with depression who self-harmed. 
Only a minority of participants (less than 25\%) recognised the logo, the name of the campaign, the ' 1 in 4 ' message and the campaign objective. This was despite the fact that three brief items of campaign materials had been posted directly to participants only 14 days before the questionnaire. There also seemed to be significant confusion between the anti-stigma Time to Change campaign and campaigns by British political parties. For example, the Conservative Party is currently using several variations on the 'time to change' themes in its marketing - 'vote to change', 'election to change'; online Fig. DS1). This was topical at the time of the survey (April 2009) in the run up to the European Parliament elections in June that year. A similar message is being promoted by most British political parties, including the Liberal Democrats. Almost as many participants believed that the Time to Change campaign was being used to promote the 'Liberal Party' and that its objective was to reduce discrimination towards mental illness $(20 \% \mathrm{v}$. $24 \%$ ). As the political campaigns are likely to intensify rather than diminish in the run up to the next UK general election (which must take place on or before June 2010), this is likely to increase the confusion and reduce the effectiveness of the Time to Change anti-stigma campaign.

A second problem of the Time to Change campaign is common to all promotional campaigns, including those of political parties and commercial product advertising. The general public is saturated with promotional literature and it is extremely difficult to get noticed and transmit any message. ${ }^{18,19}$ Even factual stories in newspapers have little impact (e.g. on voting behaviour). Consequently, marketing campaigns and newspapers tend to associate their products or stories with publicly recognised celebrities. ${ }^{18,20}$ Although the Time to Change campaign is endorsed and promoted publicly by celebrities such as Stephen Fry and Ruby Wax, they were not present on the materials used in our study.

It is unlikely that a single exposure to Time to Change materials would be effective. Although attempting to ensure repeated regular exposure over many months is prohibitively expensive, this is likely to be the only means of effecting significant 'market penetration' and attitude change.

There are now many suggested means of reducing the stigma of mental illness, including Action on Mental Health $^{12}$ and Changing Minds. ${ }^{14}$ However, responses to these campaigns tend to be small, especially if negative consequences of mental illness are also disseminated. ${ }^{21}$ Pinfold et $a l^{22}$ reported a project in which 472 English secondary school children attended mental health awareness workshops. Knox et $a l^{23}$ studied addressing stigmatised attitudes to mental illness among 4 million members of the US armed forces, which involved mandatory training on recognition of mental illness. Although this significantly reduced suicide rates, there was no effect on stigmatised attitudes. It was possible in a military or secondary school setting to insist on engagement in anti-stigma training. By contrast, involvement of the general public in any campaign is entirely voluntary.

Promoting direct interpersonal contact with people who are mentally ill may be an effective strategy, but the amount of contact required remains unknown. ${ }^{6,11,23,24}$ There was no significant effect of personal familiarity with a mentally ill person and stigmatised attitudes in our study, despite the fact that almost half of the respondents reported some familiarity with mental illness. This was also noted in an earlier study which showed no difference in the attitude of participants to people with alcoholism and those with opiate dependence, despite the fact that alcohol problems are several times more common in Britain than opiate dependence. $^{25}$ This argues against the anti-stigmatising effect of direct contact with people with certain mental illnesses. Furthermore, it would be difficult in practice to ensure that a significant proportion of the public had contact with people with a severe mental illness.

\section{Study strengths and limitations}

The AMIQ was used in this study as it is convenient and has been well validated. ${ }^{16,17,25}$ Other instruments are available, although they tend to be much longer, involve interviews or tend to address the experience of stigma by people with mental illness themselves (e.g. the Internalised Stigma of Mental Illness scale). ${ }^{16,27}$

Although there were more female respondents, age and employment status of participants were reasonably matched to that from UK census surveys and the sample appears to be a reasonable cross-section of the British public. However, the sample was self-selecting and may not generalise across the whole population. Ideally, interviews could be conducted using a quota survey of households with repeat visits for non-responders. ${ }^{5}$ Unfortunately, this is prohibitively expensive.

The study presented a hypothetical person who was mentally ill. This is less accurate than real experience. Moreover, the written views and expressed attitudes may not translate into any enduring behavioural change. It was not possible to measure stigmatised behaviour towards real people who are mentally ill.

There was no direct contact between participants and researchers, but participants are likely to make some assumptions about the potentially liberal beliefs of researchers into mental health. Hence social desirability bias may affect the results. However, the results from previous studies using the AMIQ suggest that participants had little reservation about indicating their disapproval of people with stigmatising illnesses such as substance use disorders. ${ }^{16,25}$ This would indicate that social disability bias has only a modest effect.

\section{About the authors}

Dr Abu Abraham, MB BS, MD, DipCP, MRCPsych, is Specialty Trainee in General Adult Psychiatry at the Mental Health Unit, Basildon Hospital, Nethermayne; Dr Joby Maducolil Easow, MB BS, is Staff Grade Psychiatrist (Specialty Doctor) at the Community Drug and Alcohol Service, Pitsea; Dr Palanisamy Ravichandren, MB BS, MRCPsych, is Specialty Trainee in Psychiatry, Runwell Hospital, Wickford; Dr Salman Mushtaq, MB BS, MRCPsych, is Specialty Trainee in General Psychiatry, The Taylor Centre; Linda Butterworth is a researcher at Southend Community Drug and Alcohol Service, The Taylor Centre; Dr Jason Luty, PhD, MRCPsych, is Consultant in Addictions Psychiatry, South Essex Partnership NHS Trust, and Honorary Consultant in Addictions Psychiatry, Cambridge and Peterborough Mental Health NHS Trust, The Taylor Centre, Southend-onSea, UK. 


\section{References}

1 Biernat M, Dovidio JF. Stigma and stereotypes. In The Social Psychology of Stigma (eds TF Heatherton, RE Kleck, MR Hebl): 88-125. Guilford Press, 2000

2 Corrigan P, Markowitz FE, Watson A, Rowan D, Kubiak MA. An attribution model of public discrimination towards people with mental illness. J Health Soc Behav 2003; 44: 162-79.

3 Appleby L. Safer Services. Department of Health, 1999.

4 Granello D, Pauley PS, Carmichael A. Relationship of the media to attitudes towards people with mental illness. J Consult Psychol Counsel Educ Develop 1999; 38: 89-110.

5 Crisp AH, Gelder MG, Rix S, Meltzer HI, Rowlands OJ. Stigmatisation of people with mental illnesses. Br J Psychiatry 2000; 177: 4-7.

6 Penn DL, Guynan K, Daily T, Spaulding WD, Garbin CP, Sullivan M Dispelling the stigma of schizophrenia: what sort of information is best? Schizophr Bull 1994; 20: 567-77.

7 Penn DL, Kommana S, Mansfield M, Link BG. Dispelling the stigma of schizophrenia: 2. The impact of information on dangerousness. Schizophr Bull 1999; 25, 437-46.

8 Thornton JA, Wahl OF. Impact of a newspaper article on attitudes toward mental illness. J Community Psychol 1996; 24: 17-25.

9 Mayville E, Penn DL. Changing societal attitudes towards persons with severe mental illness. Cogn Behav Practice 1998; 5: 241-53.

10 Penn DL, Martin J. The stigma of severe mental illness. Some potential solutions for a recalcitrant problem. Psychiatr Q 1998; 69: 235-47.

11 Corrigan PW, Penn DL. Lessons from social psychology on discrediting psychiatric stigma. Am Psychol 1999; 54: 765-76.

12 Office of the Deputy Prime Minister. Action on Mental Health: A Guide to Promoting Social Inclusion. ODPM, 2004 (http:// www.socialinclusion.org.uk/publications/Action_on_Mental_ Health\%20Fact_Sheets.pdf).

13 Paykel ES, Hart D, Priest RG. Changes in public attitudes to depression during the Defeat Depression Campaign. Br J Psychiatry 1998; 173: 519-22.

14 Luty J, Umoh O, Sessay M, Sarkhel A. Effectiveness of Changing Minds campaign factsheets in reducing stigmatised attitudes towards mental illness. Psychiatr Bull 2007; 31: 377-81.
15 Mehta N, Kassam A, Leese M, Butler G, Thornicroft G. Public attitudes towards people with mental illness in England and Scotland, 19942003. Br J Psychiatry 2009; 194: 278-84.

16 Luty J, Fekadu D, Umoh O, Gallagher J. Validation of a short instrument to measure stigmatised attitudes towards mental illness. Psychiatr Bull 2006; 30: 257-60.

17 Cunningham JA, Sobell LC, Chow VMC. What's in a label? The effects of substance types and labels on treatment considerations and stigma. J Stud Alcohol 1993; 54: 693-9.

18 Wilmshurst J, Mackay A. The Fundamentals and Practice of Marketing (4th edn). Butterworth, 2002.

19 Jones B, Kavanagh D, Moran M, Norton P. Politics UK (6th edn). Pearson, 2007.

20 Atkinson RL, Atkinson RC, Smith EE, Bem DJ, Nolen-Hoeksema S Hilgard's Introduction to Psychology (12th edn). Harcourt Brace, 1996.

21 Penn DL, Chamberlin C, Mueser KT. The effects of a documentary film about schizophrenia on psychiatric stigma. Schizophr Bull 2003; 29: 383-91.

22 Pinfold V, Toulmin $H$, Thornicroft G, Huxley P, Farmer P, Graham T. Reducing psychiatric stigma and discrimination: evaluation of interventions in UK secondary schools. Br J Psychiatry 2003; 182: 342-6.

23 Knox T, Smith J, Hereby H. Risk of suicide and related adverse outcomes after exposure to a suicide prevention programme in the US air force: cohort study. BMJ 2003; 327: 1376-8.

24 Wolff G, Pathare S, Craig T, Leff J. Public education for community care. A new approach. Br J Psychiatry 1996; 168: 441-7.

25 Luty J, Rao H, Arokiadass SMR, Easow JM, Sarkhel A. The repentant sinner: methods to reduce stigmatised attitudes towards mental illness. Psychiatr Bull 2008; 32: 327-32.

26 Crisp AH, Gelder M, Goddard E, Meltzer H. Stigmatisation of people with mental illness: a follow-up study within the Changing Minds campaign of the Royal College of Psychiatrists. World Psychiatry 2005; 4: $106-13$.

27 Ritsher JB, Otilingam PG, Grajales M. Internalised stigma of menta illness: psychometric properties of a new measure. Psychiatry Res 2003; 121: $31-49$. 